\title{
Racial attitudes among South African young adults: A four-year follow-up study
}

Timothy B. Smith

Brigham Young University, tbs@byu.edu

Christopher R. Stones

Rhodes University

Anthony Naidoo

Stellenbosch University

Follow this and additional works at: https://scholarsarchive.byu.edu/facpub

Part of the Counseling Psychology Commons

\section{Original Publication Citation}

Smith, T. B., Stones, C. R., \& Naidoo, A. (2003). Racial attitudes among South African young adults: A four-year follow-up study. South African Journal of Psychology, 33, 39- 43.

\section{BYU ScholarsArchive Citation}

Smith, Timothy B.; Stones, Christopher R.; and Naidoo, Anthony, "Racial attitudes among South African young adults: A four-year follow-up study" (2003). Faculty Publications. 2005.

https://scholarsarchive.byu.edu/facpub/2005 
Running Head: RACIAL ATTITUDES

Smith, T. B., Stones, C. R., \& Naidoo, A. (2003). Racial attitudes among South African young adults: A four-year follow-up study. South African Journal of Psychology, 33, 3943.

\author{
Racial Attitudes among South African Young Adults: \\ A Four-year Follow-up Study
}

Timothy B. Smith

Brigham Young University

Christopher R. Stones

Rhodes University

Anthony Naidoo

University of Stellenbosch

Correspondence concerning this manuscript should be addressed to Timothy B. Smith, Ph.D., Department of Counseling Psychology, Brigham Young University, 328 MCKB, Provo, UT, 84602-5093, USA. E-mail: Tim_Smith@byu.edu 


\begin{abstract}
Due to many social changes that have occurred in South Africa since the first democratic elections in 1994, careful scrutiny must be given to the racial attitudes of South Africa's young adults. Their degree of acceptance of the doctrine of deracialisation and reconciliation represents a hope or a warning in regard to a stable future. A follow up study was thus carried out in order to update data collected in 1995, with the hypothesis that, over time, greater acceptance of other racial groups would be reported. The authors examined the differences among the 180 Xhosaspeaking black, 89 so-called coloured, and 432 English-speaking white young adults. Data were collected using a questionnaire that assessed aspects of these groups' perceptions of themselves (identities) and their attitudes toward other racial groups (their prejudice). Statistical significance was found between groups and over time across measures.
\end{abstract}


Racial Attitudes among South African Young Adults:

\section{A Four-year Follow-up Study}

Despite the many social and political changes that have occurred in South Africa over the past decade, racism and the accompanying social divisions along racial lines continue to be central features of the South African human landscape. No doubt widespread prejudice persists owing to the power structures that were firmly entrenched by previous generations (Schlemermer \& Moller, 1997). Nevertheless, the intensity of group conflict based on perceived racial differences has diminished markedly since the transition of political power in 1994. The vision of a united "rainbow nation," although sometimes labeled as illusion, is an aspiration among increasing numbers of citizens of all colours (Moller, Dickow \& Harris, 1998).

Amid the rhetoric and political posturing, one social indicator that warrants particularly careful scrutiny is the reformation of identities and racial attitudes of South Africa's young adults. Their degree of acceptance of the doctrines of integration and reconciliation represents a hope or a warning for the future.

Past research on racism among South African adolescents has indicated that although levels of inter-group acceptance were not at the time of the studies comparable to those found in other multicultural nations, racial tolerance was nonetheless prevalent in 1995 (Smith \& Stones, 1999). However, because so many social changes have occurred since 1995, it is imperative that the cross-sectional view provided by these data be updated. The purpose of this study was to provide such an 
update, with the hypothesis that increased acceptance of each other's racial groups would be reported.

The hypothesis of improved racial attitudes among young people is supported by multiple social changes since the first democratic elections. Since that time, South Africans have been exposed to more liberal attitudes with greater social consciousness in the media and the workplace, including affirmative action polices and the Truth and Reconciliation Commission (TRC). Commentators have interpreted the corresponding call for a "rainbow nation" as an influence in changing intergroup perceptions and attitudes by which South Africans may discover a common national identity that will override racial categorization as enforced by apartheid (Duckitt \& Mphuthing, 1998).

In contrast to the new hope of and anticipation of, peace to be gained with social policy and attitude change, many consider this nothing more than post-election euphoria, with levels of happiness and optimism in the new government tapering off (See Abdi, 1999; Moller, Dickow, \& Harris 1999; Schlememer \& Moller, 1997). Carrim (2000) and Sharp (1998) both claim that new political endorsements are simply reconstructing racism to view it as a problem with individual attitudes rather than as a problem of gross differential access by various groups. Dolby $(1999,2000)$ supports this claim by arguing that the notion race is simply being rearticulated because categorizations are no longer legally bounded by apartheid. From her studies of South African youth, she contends that race after apartheid is not just a matter of discarding or embracing previous racial positions, but of renegotiating them in a new context such 
as global popular culture which is potentially able to supply youth with new sources for identification.

There are other perspectives (e.g., McConahay, 1986) that support the idea of symbolic or modern racism, suggesting that although dominant cultural beliefs about marginalized groups may become more egalitarian, underlying racial attitudes are shaped and ingrained during socialization so that they become resistant to change. Seidman (1999) and others believe that there is no real sense of how South Africans actually experienced rigid racial categories, concluding that no one can really tell how racial patterns might change in the post-apartheid era or how reformers might best seek to change them. Further, reported social indicators like gaps in income between Whites and Blacks do not show any narrowing or softening of the inequality, and violence and crime across racial lines has become rampant thus continuing to be a threat to stability in South Africa (Schlemmer \& Moller, 1997).

Despite these assertions, many scholars continue to argue that social change will lead to improved interracial relations (Allan \& Allan, 2000; de la Rey, 1991; Duckitt \& Mphuthing, 1998; Fisher \& Sonn, 1999; Smith \& Stones, 1999; Swartz \& Drennan, 2000). The current study was conducted to assess the current levels of racial attitudes in a sample of young adults and to compare those results with an equivalent sample assessed four years earlier.

\section{Method}

To discern changes in racial attitudes over time, data collected in 1995 from adolescent high school students (Smith \& Stones, 1999) were compared against data 
collected in 1999 from young adult college students. The median ages of the two samples were four years apart, corresponding with the time differential in data collection. Thus the two samples were from the same age cohort.

In the 1995 sample, 180 participants were Black (78\% Xhosa), 89 were Afrikaans-speaking individuals of mixed racial decent (so-called Coloureds ${ }^{1}$ ), and 432 were English-speaking Whites. The average age was 15.6 years, with no significant age differences between racial groups. Students were nearly evenly distributed across standard levels 6 to 10 . Many (47\%) reported coming from middle-class homes, but White English-speakers reported higher socio-economic levels than the two other groups $(\underline{F}=6.0 ; \underline{p}<.01)$. Of the participants, $33 \%$ were raised predominantly outside of the Eastern Cape.

In 1999, 429 young adults attending Rhodes University and the University of the Western Cape completed the same racial attitude measures as the 1995 sample. Of these participants, 122 were Black (58\% Xhosa), 73 were so-called Coloured, and 234 were English-speaking Whites. Many (43\%) of the respondents were first-year students; $34 \%$ were second-year students, and $23 \%$ were third-year students. Although $40 \%$ reported coming from middle-class homes, White English-speakers reported higher socio-economic levels than the other two groups $(\underline{F}=96.0 ; \underline{p}<.001)$. The participants were from the Eastern Cape (26\%), Western Cape (26\%), Gauteng (23\%), Kwa-Zulu Natal (15\%), and other provinces (10\%).

At both assessments, the participants completed the Anti-White Scale (AWS) and the Subtle Racism Scale (SRS). The AWS (Duckitt \& Farre, 1994) assesses attitudes 
toward White participation in the social, economic, and political contexts of South Africa. It evaluates resentment/forgiveness of Whites and the perceived necessity for Whites to make restitution for the wrongs of Apartheid. The SRS (Duckitt, 1991, 1993) evaluates acceptance of inter-racial contact and aspiration for equal status among all races. Both the SRS and the AWS were developed in South Africa specifically for use with South African populations. These scales have demonstrated acceptable reliability coefficients (ranging from 0.91 to 0.76 ) in previously published studies, and have been evaluated as having sufficiently acceptable content and construct validity (Duckitt, 1991; 1993; Duckitt \& Farre, 1994). To assess ethnic identity, the Multigroup Ethnic Identity Measure (MEIM) (Phinney, 1992) was administered to the 1999 sample. This measure has been used in multiple studies across many ethnic groups with generally exceptional psychometric performance (e.g., Roberts et al., 1999).

Results

\section{Cross-Sectional Analyses of 1999 Data}

Means and standard deviations on the three dependent measures are reported according to group in Table 1 . The mean values on the AWS indicated that Black and so-called Coloured participants had moderately tolerant attitudes, while the White sample had clearly pro-White attitudes. The mean values on the SRS indicated that all three groups tended to have moderately tolerant attitudes toward other groups. The mean values on the MEIM indicated that all three groups tend to have a moderately positive ethnic identity. 
A multivariate analysis of variance (MANOVA) was conducted to see if the differences between groups were statistically significant on the three dependent measures. This analysis yielded statistically significant results $(\underline{F}=38.7, \underline{p}<.001)$, and post hoc univariate analyses of variance (ANOVAs) were then conducted. Results indicated that the Black participants endorsed the AWS to a significantly greater extent than did the endorsement by so-called Coloured participants, whose endorsement was significantly more strong than that of the White participants $(\underline{F}=60.9, \underline{p}<.001)$. White participants were least likely to endorse the SRS, indicating significantly less interracial tolerance among this group $(\underline{F}=38.6, \underline{p}<.001)$. Black participants were the most likely to endorse the MEIM, indicating that this group had a significantly more positive ethnic identity than the other two groups $(\underline{F}=5.8, \underline{p}<.01)$.

To facilitate interpretation of the results of the post hoc ANOVAs, effect sizes were calculated as an estimate of the magnitude of group differences (Glass \& Hopkins, 1984). Often more useful than traditional inferential hypothesis testing methods (such as ANOVAs), the effect size is a descriptive (not inferential) statistic used to assess the practical significance of group differences (Borg \& Gall, 1989; Shaver, 1993). The effect size statistics (ES) reported below were computed by dividing the difference between mean scores of the two groups by their pooled standard deviation. Practical significance can be evaluated using Cohen's (1988) standards for effect sizes, in which absolute values around or below .20 are considered small, those around .50 are considered moderate, and those around or above .80 are considered large. Conceptually, it is useful to think of these values as the percentage of a standard deviation of difference between 
scores. Thus an effect size of .5 is equivalent to a mean difference of one-half of a standard deviation.

Effect size differences between groups for the AWS, SRS, and MEIM are reported in Table 2. Results of analyses with the AWS indicated large to very large practical differences between groups. The mean score of White participants was about one standard deviation higher than those of the other two groups, which differed from one another by one-half of a standard deviation unit. For the SRS, the difference between the mean scores of White participants and those of the other two groups was also notably large. Differences on the MEIM were smaller, with the difference between the mean scores of Black and so-called Coloured participants being about one-half of a standard deviation unit.

Comparisons of 1999 and 1995 Data

To test the hypothesis that racial attitudes had improved in all groups over the four-year period, data from the 1999 sample were compared with those of the 1995 sample. To test if the differences across time by group were statistically significant, a MANOVA was conducted. This analysis yielded statistically significant results $(\underline{F}=9.52$, $\underline{\mathrm{p}}<.001$ ), and a post hoc univariate tests was then conducted for each group separately. Results indicated that for the Black participants, the changes in scores on the AWS and SRS were not statistically significant ( $\underline{p}=.07$ and .11 , respectively). For the so-called Coloured participants, the changes in scores were statistically significant on the AWS $(p<.001)$ but not on the SRS $(p=.07)$. For the White participants, the 
changes in scores were statistically significant on both the AWS $(\underline{p}=.001)$ and SRS ( $p$ $=.02)$.

As above, effect sizes were calculated to facilitate the interpretation of the post hoc univariate analyses. As recorded in Table 1, the greatest difference across time occurred with the AWS scores of the so-called Coloured participants. All of the remaining differences were small to moderately small. The results with the SRS scores are particularly notable because the effect sizes for the Black participants were almost exactly the same as those for the White participants, which were actually lower than the effect size for the so-called Coloured participants. This pattern may be explained by the fact that inferential statistics depend on the number of participants in each group, whereas the effect size statistic does not. Because there were fewer Black and socalled Coloured participants, the inferential statistics calculated for those groups had notably less statistical power than the results computed for the White participants, making it more likely that a true difference would be incorrectly rejected (a Type II error). The effect size analyses seem to indicate that a Type II error did indeed occur (see Shaver, 1993 for a description of how this can occur). Even though the differences across time for Black and so-called Coloured participants did not quite reach statistical significance, they were of equivalent practical significance to those of the White participants.

Thus, the data show that all three groups demonstrated small increases in racial tolerance. These increases were comparable across groups. However, the data also show notable increases in positive attitudes toward Whites among the so-called 
Coloured participants, small increases in positive attitudes toward Whites among Black participants, and moderately small decreases in pro-White attitudes among the White participants.

\section{Discussion}

Considering the entrenched resiliency of racial attitudes that has been widely noted in the literature (McConahay, 1986; Pratto, Sidanius, Stallorth \& Malle, 1994), the finding of an apparent shift toward increased tolerance is heartening. These findings may indicate that some South African young adults are internalizing anti-racist messages present in their society and are acknowledging the need to make personal level changes.

Nevertheless, given the multiple political and social initiatives undertaken to reduce racism in South Africa between 1995 and 1999, it is noteworthy that the measured change in tolerance was small and, in some cases not quite statistically significant. These results seem to confirm the intransigence of racial attitudes noted so widely in the literature.

In interpreting these results, however, several limitations of the study should be noted. First and foremost, a cohort comparison design like that used in this study does not control for certain threats to research validity. It is therefore possible that different samples yielded different results across time by chance alone, regardless of intervening events. Moreover, although many of the participants were raised in other areas of the country, the samples were drawn from these currently living in the Eastern and Western Cape provinces, limiting the generalisability of the findings. Also the 
educational backgrounds of the participants recruited for this study were of a homogeneity that makes it likely that the results would not be typical to those with different educational experiences. Further, because this study targeted a specific age cohort, the results cannot be assumed to represent South Africans from different age groups.

Another limitation is that this study addressed global interracial tolerance (SRS) and Anti-White sentiment (AWS) but not tolerance or prejudice toward other groups. Due to South Africa's racial diversity and its complex history of interactions between different groups, it might be more informative to address attitudes toward other specific groups as well. Further, since according to the theory of planned behaviour (Ajzen, 1991) intentions are the best predictors of behaviours, so the research design could have been improved by using a scale that measures intentions rather than attitudes.

Among the young adult participants in the 1999 sample, the large intergroup differences were equivalent to those found in the 1995 sample of adolescents (Smith \& Stones, 1999). Although racial attitudes were mildly more tolerant in the 1999 sample, South African ethnic groups continue to have very different perceptions of racial issues. For years, these group differences have been noted across multiple studies (e.g., Kinloch, 1985). Authors have called the persistent group differences "the legacy of Apartheid" (Beall, Crankshaw \& Parnell, 2000; Carton, 2000; Kenny \& Webster, 1998; Moodley \& Adam, 2000; Olufemi, 1998; Webster, 1999). Yet, despite the persistence of group differences noted again in this study, there is still the hope that further social and political changes will continue to increase tolerance among groups. 
However, the large effect size differences across groups at both assessments clearly indicate that English-speaking Whites still have a long way to go to become as tolerant of racial differences as their Black and so-called Coloured compatriots. Similarly, social identity theory (Blascovich et al., 1997; Tajfel, 1978; Yzerbyt et al., 1995) lends support to the idea that members of groups that experience more prejudice than others are more motivated to maintain the distinction between their own group and the out groups. The results here can also support earlier findings which report just how negatively Whites appear to view the future, as compared to other groups (See Schlemmer \& Moller,1997; Duckitt \& Mphuthing, 1998 for a complete review). Further, the events of the intervening years may have been more profound for Whites, whose intolerant attitudes have been continuously challenged by governmental policies and by the popular media. In Dolby's (2000) research involving identity construction among South Africa's youth, she noted that running through the minds of White students in her study was the fear of marginalisation and the sense that the present generation is being forced to compensate blacks for past mistreatment.

The mean score differences noted between groups may also help to explain the finding that the Black and so-called Coloured participants apparently did not change as much as the White participants did: Their attitudes were already predominantly positive. Thus, an assessment ceiling effect may have unduly limited the range of difference possible on the AWS and SRS.

Explanations for the notable increases of positive attitudes toward Whites by the so-called Coloured participants may be reflected in what Fisher and Sonn (1999) explain 
as an attempt to retain their relative advantage over Blacks that was allotted to them during apartheid. They also note how historically the so-called Coloureds had a heritage of identifying with, and aspiring to be, members of the White community. Unterhalter (1975) found that in regard to social change, urban so-called Coloureds tended to reject rather than align themselves with the Blacks, and they generally did not increase ties with the Black Power Movement. However it is important to mention here that reports of these attitudes are historical, and may not adequately reflect the current thinking of so-called Coloureds. It may be more likely that their attitudes towards the Whites significantly improved because they may not be as motivated as the Whites to maintain social distinction between their group and the out group. Their relatively low ethnic identity scores may support this idea since unstable ethnic identity may imply that self-esteem is being invested than in one's group, resulting in less derogation toward out-groups and less in-group favouritism. The relatively low ethnic identity scores of the so-called Coloureds may relate to the association of marginalisation with instability (Grove, 1973; Kinloch, 1985; Finchilescu \& de la Rey, 1991). More research is needed, of course, before concluding the latter and the previous speculations concerning this group.

One reason the apparent attitude stability among Black participants may exist is that their group currently has greater political power so that the perceived need to become even more tolerant may be minimized. Further, groups that perceive themselves to be in positions of power often do not perceive the need to change (Duckitt \& Mphuthing, 1998). But, because clear economic and social advantages are 
still maintained by Whites in the country, this later interpretation is speculative. A more likely reason for the lack of differences is that the relatively low number of Black and so-called Coloured participants included in the sample unduly reduced the statistical power necessary to show significant differences. These results should therefore need to be replicated on larger samples.

\section{Summary}

As stated in the introduction, the degree to which the youth of South Africa accept the doctrine of deracialisation and reconciliation represents a hope or a warning for the effort to build a stable future for this country. The present results, although limited in their generalisability, may indicate that some South African young adults are internalizing anti-racist messages present in their society and thus acknowledging the need to make personal level changes. Though evidence of change is present in this study, the magnitude of these changes as demonstrates that interracial tolerance remains a goal requiring even more social change if a truly "rainbow nation" in South Africa is to be realized. 


\section{References}

Abdi, A.A. (1999). Identity formations and deformations in South Africa: A historical and contemporary overview. Lournal of Black Psychology, 3, 147-163.

Ajzen, I. (1991). The theory of planned behavior. Organizational Behavior and Human Decision Processes, 50, 179-211.

Allan, A., \& Allan, M. (2000). The South African Truth and Reconciliation Commission as a therapeutic tool. Behavioral Sciences and the Law, 18, 459-477.

Beall, J. Crankshaw, O. \& Parnell, S. (2000). Local government, poverty reduction and inequality in J ohannesburg. Dept Social Policy \& Administration, London School Economics, UK [e-mail: j.beall@lse.ac.uk].

Blascovich, J., Wyer, N.A, Swart, L.A., \& Kibler, J.L.( 1997). Racism and racial catagorization. L Lurnal of Personality and Social Psychology, 72, 1364-1372.

Borg, W. R., \& Gall, M. D. (1989). Educational research: An introduction (5th ed.). New York: Longman.

Bornman, E., \& Appelgryn, A. (1999). Predictors of ethnic identification in a transitionary South Africa. South African Journal of Psychology, 29, 62-71.

Carrim, N. (2000). Critical anti-racism and problems in self-articulated forms of identities. Race, Ethnicity, and Education, 3, 27-44.

Carton, B. (2000). Unfinished exorcism: The legacy of apartheid in democratic Southern Africa. Social-Justice, 27, 116-127.

Cohen, J. (1988). Statistical power analysis for the behavioral sciences (2nd ed.).

Hillsdale, NJ: Erlbaum.

de la Rey, C. (1991). Intergroup relations: Theories and positions. In D. Foster and J. LouwPotgieter (Eds.) Social psychology in South Africa (pp. 27-56). Johannesburg: Lexicon. 
Dolby, N. (1999). Youth and the Global Popular: The Politics and Practices of Race in South Africa. European J ournal of Cultural Studies, 2, 291-309.

The shifting ground of race: The role of taste in youth's production of identities. Race, Ethnicity and Education, 3, 7-23.

Duckitt, J. (1993). Further validation of a subtle racism scale in South Africa. South African Journal of Psychology, 23, 116-119.

Duckitt, J. (1991). The development and validation of a subtle racism scale in South Africa. South African Journal of Psychology, 21, 233-239.

Duckitt, J ., \& Farre, B. (1994). Right-wing authoritarianism and political intolerance among Whites in the future majority-rule South Africa. The Journal of Social Psychology, 134, 735-741.

Duckitt, J ., \& Mphuthing, T. (1998). Political power and race relations in South Africa: African attitudes before and after the transition. International Society of Political Psycholgy, 19, 809-832.

Finchilescu, G., \& de la Rey, C. (1991). Understanding intra-group variations in prejudice: The role of perceived legitimacy and stability. South African Journal of Psychology, 21, 225-232.

Fisher, A., \& Sonn, C.C. (1999). Aspiration to community: Community responses to rejection. Lournal of Community Psychology, 27, 715-725.

Glass. G., \& Hopkins, K. (1984). Statistical methods in education and psychology. Prentice Hall: Englewood Cliffs, NJ.

Grove, D. (1973). Marginality and nonconformist behavior. South African Lournal of Sociology, 7, 22-35. 
Kenny, B., \& Webster, E. (1998). Eroding the core: Flexibility and the resegmentation of the South African labour market. Critical-Sociology, 24, 216-243.

McConahay, J. (1986). Modern racism, ambivalence, and the Modern Racism Scale. In J. Dovidio (Ed): Prejudice, discrimination, and racism. (pp. 91-125). San Diego, CA: Academic Press.

Kinloch, G. (1985). Racial attitudes in South Africa: A review. Genetic, Social and

General Psychology Monographs, 111, 261-281.

Moller, V., Dickow, H., \& Harris, M. (1999). South Africa's "rainbow people," national pride and happiness. Social Indicators Research, 47, 245-280.

Moller, V., \& Schlemmer, L. (1989). South African quality of life: A research note. Social Indicators Research, 21, 279-291.

Moodley, K., \& Adam, H. (2000). Race and nation in post-apartheid South Africa Current-Sociology 48, 51-69.

Olufemi, O. (1989). Street homelessness in J ohannesburg inner-city: A preliminary survey. Environment-and-Urbanization, 10, 223-234.

Phinney, J . (1992). The multigroup ethnic identity mesaure: A new scale for use with diverse groups. Lournal of Adolescent Research, 7, 156-176.

Pratto, F., Sidanius, J., Stallworth, L., \& Malle, B. (1994). Social dominance orientation: A personality variable predicting social and political attitudes. Journal of Personality and Social Psychology, 67, 741-763.

Roberts, R., Phinney, J., Masse, L., Chen, Y., Richard, R., Roberts, C., \& Romero, A. (1999). The structure of ethnic identity of young adolescents from diverse ethnocultural groups. Lournal of Early Adolescence, 19, 301-322. 
Schlemmer, L., \& Moller, V. (1997). The shape of South African society and its challenges. Social Indicators Research, 41, 15-50.

Swartz, Leslie, \& Drennan, G. (2000). The cultural construction of healing in the truth and reconciliation commission: Implications for mental health practice. Ethnicity and Health, 5, 205-213.

Seidman, G. (1999). Is South Africa Different? Sociological Comparisons and Theoretical Contributions from the Land of Apartheid. Annual Review of Sociology, 25, 419-440.

Sharp, J. (1998). 'Non-Racialism' and Its Discontents: A Post-Apartheid Paradox. International Social Science Journal, 50, 243-252.

Shaver, J. (1993). What statistical significance testing is, and what it is not. Journal of Experimental Education, 61, 293-316.

Smith, T., \& Stones, C. (1999). Identities and racial attitudes of South African and American adolescents: A cross-cultural examination. South African J ournal of Psychology, 29, 23-29.

Tajfel, H. (1978) The psychological structure of intergroup relations. In H. Tajfel (Ed.), Differentiation between social groups. London: Academic Press.

Unterhalter, J. (1975). The sociology of South Africa: A review article. Lournal of Southern African Studies, 1, 247-252.

Webster, E.C. (1999). Race, labour process and transition: The sociology of work in South Africa. Society-in-Transition, 30, 28-42. 
Yzerbyt, V.Y., Leyens, J.P., \& Bellour, F. (1995). The ingroup overexclusion effect: Identity concerns in decisions about group membership. European Journal of Social Psychology, 25, 1-16. 
Table 1.

Ranked Group Means on Measures of Racial Attitudes and Ethnic I dentity in the 1999 and 1995 Samples and Effect Size Differences Across Time.

\begin{tabular}{llc}
\multicolumn{1999}{l}{ Sample } & & 1995 Sample & $\underline{E S}^{*}$ \\
Mean SD & Mean SD & Difference
\end{tabular}

Anti-White Sentiment (AWS)

$\begin{array}{lrrrrr}\text { Black participants } & 4.90 & 0.96 & 4.69 & 1.11 & .20 \\ \text { So-called Coloured participants } & 5.29 & 0.66 & 4.84 & 0.87 & .59 \\ \text { White English-speaking participants } & 5.84 & 0.58 & 6.04 & 0.68 & -.32\end{array}$

Subtle Racism (SRS)

$\begin{array}{llllll}\text { White English-speaking participants } & 3.55 & 0.87 & 3.72 & 0.86 & -.20 \\ \text { So-called Coloured participants } & 2.93 & 0.76 & 3.13 & 0.68 & -.28 \\ \text { Black participants } & 2.75 & 0.77 & 2.89 & 0.75 & -.18\end{array}$

Ethnic Identity (MEI M)

Black participants

$3.06 \quad 0.61$

White English-speaking participants $2.88 \quad 0.51$

So-called Coloured participants $\quad 2.78 \quad 0.53$

NOTE: Response means were derived by dividing mean scores by the number of items on the scale. AWS and SRS items were rated on a 1 to 7 scale, with 1 being "strongly agree" and 7 being "strongly disagree". MEIM items were rated on a 1 to 4 scale, with 1 being "strongly disagree" and 4 being "strongly agree." Therefore, low scores on the AWS indicate greater anti-White sentiment; low scores on the SRS indicate greater interracial tolerance; and low scores on the MEIM indicate weaker ethnic identity. (The MEI M was administered in 1999 only.)

${ }^{*} \mathrm{ES}=$ Effect size. This statistic indicates the magnitude of difference between the 1999 and 1995 data by subtracting the mean scores and dividing the result by the pooled standard deviations. 
Table 2.

Effect Size Differences Across Groups, 1999 Data.

\begin{tabular}{lccc}
\hline Groups Contrasted & AWS & SRS & MEIM \\
\hline & & & \\
\hline Black vs. Coloured Participants & .48 & .23 & .49 \\
Black vs. White Participants & 1.22 & .98 & .32 \\
Coloured vs. White Participants & .89 & .76 & .19 \\
\hline
\end{tabular}




\section{Footnote}

${ }^{1}$ Dissatisfaction with the term "Coloured," which was coined by colonial powers, has led to the recent practice of referring to this group as the "so-called Coloureds." 